\title{
Mechanical and Electrical Properties of a CFETR CSMC Conductor Under Transverse Mechanical Loadings
}

\author{
Yi Shi ${ }^{\circledR}$, Jinggang Qin, Yu Wu, Fang Liu ${ }^{\circledR}$, Huajun Liu ${ }^{\circledR}$, Huan Jin, Qiangwang Hao, A. Nijhuis, \\ K. Yagotintsev, and Chao Zhou
}

\begin{abstract}
The central solenoid model coil (CSMC) project of the China Fusion Engineering Test Reactor was launched in 2014 to verify the technological feasibility of a large-scale superconducting magnet at the Institute of Plasma and Physics Chinese Academy of Sciences. The short twist pitch design recommended by CEA is chosen for the CSMC $\mathrm{Nb}_{3} \mathrm{Sn}$ cable-in-conduit conductors. In order to better understand the evolution of transport properties and coupling losses related to the effect of electromagnetic load cycles, the mechanical and electrical properties were measured and investigated employing a special cryogenic press facility for the transverse mechanical loadings. The results show that the transverse compression $\left(d_{\mathrm{y}}\right)$ versus applied load force $\left(F_{\mathrm{y}}\right)$ is different from first to subsequent loading cycles. This mechanical behavior can be interpreted by the combination of strands bending between the crossovers and strands deformation at the crossovers. The fitting relations of $d_{\mathrm{y}}$ versus $F_{\mathrm{y}}$ are also presented. The evolution of interstrand contact resistance $\left(R_{\mathrm{c}}\right)$ in the cabling stages with cyclic history and pressure effects are discussed. In addition, a fitting relation of $\boldsymbol{R}_{\mathrm{c}}$ versus $\boldsymbol{F}_{\mathrm{y}}$ is presented based on a combination of strand's microsliding and copper matrix resistivity. A clear correlation between intrapetal resistance $R_{\mathrm{c}}$ and coupling loss is also found.
\end{abstract}

Index Terms-Cable-in-conduit conductors (CICC), contact resistance, mechanical properties, transverse load.

\section{INTRODUCTION}

$\mathbf{T}$ HE China Fusion Engineering Test Reactor (CFETR) will be built as a compliment to ITER [1], [2]. The central solenoid model coil (CSMC) project has been constructed in 2014 to develop and verify large-scale superconducting magnet technology for CFETR at the Institute of Plasma and Physics Chinese Academy of Sciences (ASIPP) [3]. The design of the

Manuscript received July 20, 2017; revised December 26, 2017; accepted January 2, 2018. Date of publication March 27, 2018; date of current version May 17, 2018. This work was supported in part by the National Natural Science Foundation of China under Grant 51507174 and Grant 51477112 and in part by the National Magnetic Confinement Fusion Science Program of China under Grant 2014GB105004 and Grant 2014GB105001. This paper was recommended by Associate Editor M. C. Jewell. (Corresponding author: Fang Liu.)

Y. Shi, J. Qin, Y. Wu, F. Liu, H. Liu, H. Jin, and Q. Hao are with the Hefei institute of Physical Science, Chinese Academy of Sciences, Hefei 230031, China (e-mail: fangliu@ipp.ac.cn; liuhj@ipp.ac.cn).

A. Nijhuis, K. Yagotintsev, and C. Zhou are with the Faculty of Science and Technology, University of Twente, Enschede 7500AE, The Netherlands.

Color versions of one or more of the figures in this paper are available online at http://ieeexplore.ieee.org.

Digital Object Identifier 10.1109/TASC.2018.2820047
CSMC calls for the use of cable-in-conduit conductors (CICC) composed of $\mathrm{Nb}_{3} \mathrm{Sn}$.

For the cable layout the short twist pitch (STP) design recommended by The French Alternative Energies and Atomic Energy Commission (CEA) is chosen for the CFETR-CSMC conductor because of the better transport performance against cyclic electromagnetic (EM) force loading through an optimization analysis and the test for ITER $\mathrm{Nb}_{3} \mathrm{Sn}$ conductors [4], [5]. The successful testing of the $\mathrm{Nb}_{3} \mathrm{Sn}$ CICC short sample for the CFETR-CSMC in SULTAN has been performed in the spring of 2016 and stable transport performance against cycles is obtained [6].

The cyclic EM force loading under operating conditions will induce the movement and plastic deformation of strands in $\mathrm{Nb}_{3} \mathrm{Sn} \mathrm{CICC}$, which results in the degradation of transport performance affecting current sharing, redistribution, and stability, as well as changes of the ac loss. Therefore, the cable deformation and interstrand contact resistance $\left(R_{c}\right)$ are the crucial parameters for understanding the evolution of transport performance and ac loss with load cycles [7].

A cryogenic press has been employed to investigate the mechanical and electrical behavior of a CFETR-CSMC CICC sample under transverse cyclic load simulating the EM force on the conductor at the University of Twente. Through the measurements, the mechanical characteristics for cyclic loading are discussed, as well as the effect on interstrand $R_{c}$.

\section{CONDUCTOR AND EXPERIMENT PROCEDURE}

\section{A. $\mathrm{Nb}_{3} \mathrm{Sn}$ Cable-in-Conduit Conductor}

Internal tin processed $\mathrm{Nb}_{3} \mathrm{Sn}$ strands provided by Western Superconducting Technologies Company, Ltd., were employed to meet the specifications of the CFETR-CSMC. The detailed parameters of the $\mathrm{Nb}_{3} \mathrm{Sn}$ strand are described in [3].

There is enough evidence to show that the lateral support of strands plays a key role in the degradation behavior of $\mathrm{Nb}_{3} \mathrm{Sn} \mathrm{CI}-$ CCs. The main parameters affecting lateral support are the cable twist pitches and void fraction [8], [9]. It is found that the STP option has the better transport performance against the load cycles based on a large number of ITER conductor samples tested in SULTAN. So the STP option is the basic design adopted for the CFETR-CSMC $\mathrm{Nb}_{3} \mathrm{Sn}$ CICC. In order to develop the $\mathrm{Nb}_{3} \mathrm{Sn}$ CICC cabling method with STP for CFETR-CSMC, ASIPP has 
TABLE I

DETAIL CHARACTERISTICS OF $\mathrm{NB}_{3} \mathrm{SN}_{\mathrm{N}} \mathrm{CICC}$ FOR CFETR CSMC

\begin{tabular}{lcc}
\hline \hline Property & unit & value \\
\hline Cabling layout & \multicolumn{2}{c}{$(2 \mathrm{SC}+1 \mathrm{Cu}) \times 3 \times 4 \times 4 \times 6$} \\
\hline Final outer diameter & $\mathrm{mm}$ & 32.6 \\
Void fraction & & $32.7 \%$ \\
Twist pitch sequence & $\mathrm{mm}$ & $24 / 49 / 89 / 160 / 450$ \\
Petal stainless steel wrap & & $70 \%$ overlap \\
Cable stainless steel wrap & & overlapped \\
\# of SC strand & & 576 \\
$\#$ of copper wires & & 288 \\
Conduit dimension & $\mathrm{mm}$ & $49 \times 49$ \\
Conduit material & & $316 \mathrm{LN}$ \\
Heat treatment schedule ${ }^{\circ} \mathrm{C} / \mathrm{h}$ & $210 / 50+340 / 25+450 / 25+575 / 100+650 / 1$ \\
in vacuum or Ar atmosphere & 00 & \\
\hline \hline
\end{tabular}

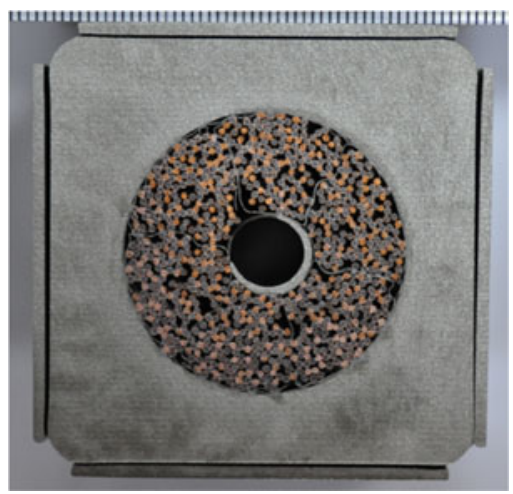

Fig. 1. Cross-section of the CIC conductor.

developed the cabling technology and measured the strand deformation, as well as critical current $\left(I_{c}\right)$ degradation in the cabling process. Subsequently, a prototype CICC manufacture and visual inspection of cable damage with deformation has been performed, which ensures the feasibility of manufacturing technology for $\mathrm{Nb}_{3} \mathrm{Sn}$ CICC [10], [11]. The detailed structure characteristics of the $\mathrm{Nb}_{3} \mathrm{Sn}$ CICC are shown in Table I. Fig. 1 shows the cross section of the $\mathrm{Nb}_{3}$ Sn CICC.

\section{B. Experiment Procedure}

The length of the cable sample in the cryogenic press is $400 \mathrm{~mm}$. The cable jacket is cut in half with a separation so that the applied load force $\left(F_{y}\right)$ can compress the bundle freely. The virgin state of the cable is maintained by the locked void-fraction method [10]. The stress inside the cable is calculated for two different configurations by using FEM with a computer code called ELCUT: First, for the case of the cable in the cryogenic press, and second, for the real Lorentz force distribution in the ITER magnet. In order to have a representative force with respect to the interstrand resistance and coupling loss, it is suggested to take a peak load of about $400 \mathrm{kN} / \mathrm{m}$ in the cryogenic press [12]. $F_{y}$ is measured by six strain gauges installed on the sides of the plate that transfers the pressure to the conductor sample.

The cable transverse compaction displacement $\left(d_{y}\right)$ and $R_{c}$ of different cabling stages are monitored at each of the loads. $d_{y}$ is measured by six sets of calibrated extensometers mounted on two sides of the sample symmetrically. $R_{c}$ is measured with the four-point method applying the $50 \mathrm{~A}$ current supplied to a
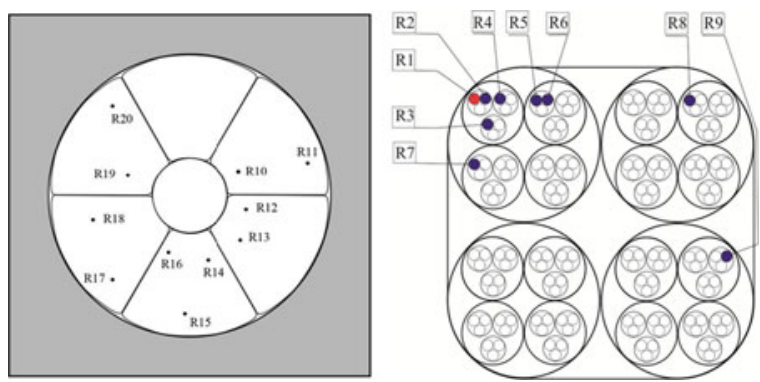

Fig. 2. Scheme of the strand selection for $R_{c}$ measurement.

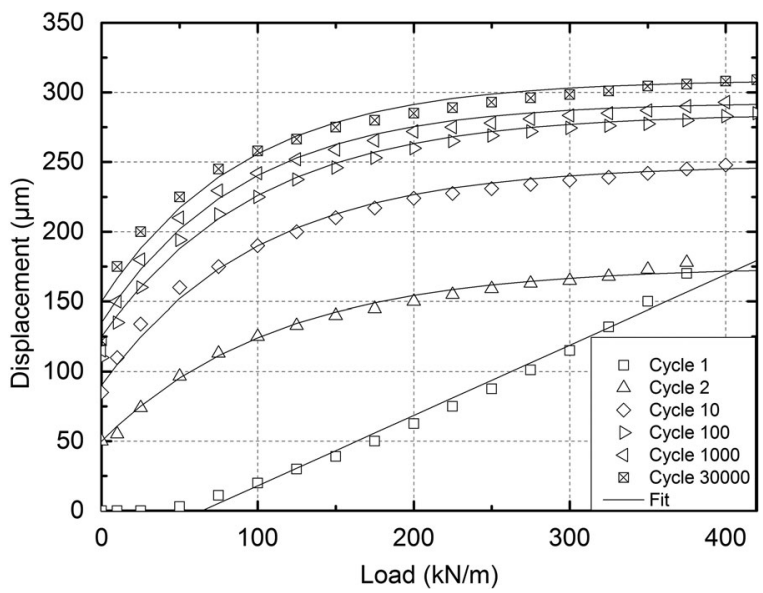

Fig. 3. Displacement versus applied load from 1st to 30 000th cycles with fitted curve by (2).

selection of strand pairs shown in Fig. 2. $R_{c}$ value is determined by

$$
R_{c}=\frac{V}{I} \cdot l \quad[\Omega \cdot \mathrm{m}]
$$

where $V$ is the measured voltage, $I$ is the applied current, and $l$ is the sample length $(400 \mathrm{~mm})$. The detailed procedure on $d_{y}$ and $R_{c}$ measurement is described in [13]-[15].

\section{Mechanical PRoperties}

$d_{y}$ of the cable as a function of $F_{y}$ is the main measurement quantity for the CICC's mechanical property. The mechanical load cycles are repeated up to 30000 cycles and the results are shown in Fig. 3. All measurements are carried out in liquid helium at $4.2 \mathrm{~K}$.

$d_{y}$ versus $F_{y}$ hysteretic behavior is in agreement with what has been observed in ITER $\mathrm{Nb}_{3}$ Sn CICCs [14]. At first loading, $d_{y}$ versus $F_{y}$ curve is approximately linear when the load force is larger than $50 \mathrm{kN} / \mathrm{m}$. This is different from the subsequent loading where the curve is evidently nonlinear and tends to the saturation with increasing number of cycles. The maximum value of $d_{y}$ is $309 \mu \mathrm{m}$ after 30000 load cycles. The difference of $d_{y}$ versus $F_{y}$ correlation between 2 and 30000 load cycles indicates that there is amount of plastic deformation in the cable.

This mechanical behavior can be explained as follows [15]. As we known, the cable deformation mainly originates from strands bending between the crossovers and strands deformation 
at the crossovers. At the first loading, the contact area at the crossovers decreases because of the microsliding of strands, so the deformation at the crossovers is not obvious and the main deformation is the strand bending independent of the load. In the subsequent cycles, deformation at the crossovers plays a lead role because the strands undergo the plastic deformation at the crossovers; meanwhile, the contact area also increases with load. This makes $d_{y}$ increase difficult and leads to a nonlinear $d_{y}$ versus $F_{y}$ behavior.

The precise simulation of the $d_{y}$ versus $F_{y}$ correlation is difficult due to the complex microsliding and plastic deformation of strands. Nijhuis et al. proposed the TEMPLOP model for simulating the strand and cable deformation, but this model needs relevant strand and cable parameters of which some are obtained by the experiment [15]. Here, a simplified fit model is used in (2), which is proposed by Lu et al. first to describe the $d_{y}$ versus $F_{y}$ correlation for different load cycles [16]

$$
d_{y}=\left\{\begin{array}{l}
A+B \cdot\left(1-e^{-C \cdot F}\right)(N \geq 2) \\
A_{0}+B_{0} \cdot F\left(F>F_{0}, N=1\right)
\end{array}\right.
$$

where $A, B, A_{0} B_{0}$, and $C$ are fitted parameters describing the dependence on cycles, $F_{0}$ is a constant. This simple formula described the $d_{y}$ versus $F_{y}$ behavior is in good agreement with the measurement results shown in Fig. 3.

\section{ELECTRICAL PROPERTIES}

It is known that $R_{c}$ is not only one of the most important factors affecting coupling losses of cable, but also represents the mechanical characteristics that determine the degradation of transport performance [17]-[19]. However, prediction of $R_{c}$ is difficult because it is affected not only by cable pattern and strand parameters, but also transverse EM force and load cycling. So, it is necessary to measure $R_{c}$ at cryogenic temperature as a function of transverse load and number of load cycles.

\section{A. Pressure Effect of Contact Resistance}

$R_{c}$ between strands from the first cabling stage is monitored with the different loading cycles against the transverse load from 0 up to $417 \mathrm{kN} / \mathrm{m}$. Fig. 4 shows the measurement results. Based on the measurement, we found that the $R_{c}$ versus $F_{y}$ curve shows an approximately linear increase at first loading. However, with subsequent loading, the $R_{c}$ versus $F_{y}$ curves shows the clear nonlinear decrease and saturation after enough load cycles.

It is natural to understand that an increasing transverse loading will leads to an increasing contact area and also a decreasing $R_{c}$. So, it is important to find the reason why $R_{c}$ increases with $F_{y}$ linearly at the first loading.

In general, the measured $R_{c}$ is mainly determined by the contact areas and copper matrix of the strands [16]. For initial state, the contact area may decrease with transverse load increasing due to microsliding of strands [14], [20]. On the other hand, the resistivity of the copper matrix may also increase because of the deformation [21]. So, $R_{c}$ shows the increase with $F_{y}$ increasing at the first loading.

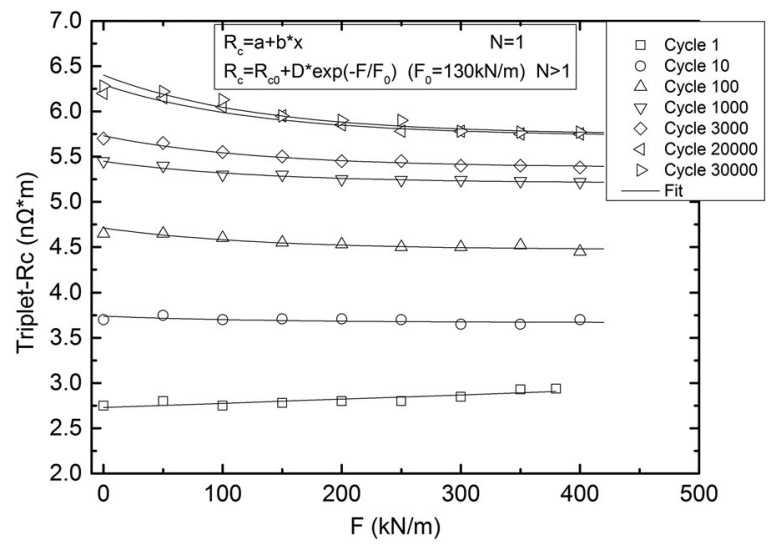

Fig. 4. $\quad R_{c}$ of first cabling stage versus $F_{y}$ from 1 st to 30 000th cycles with fitted curve by (3).

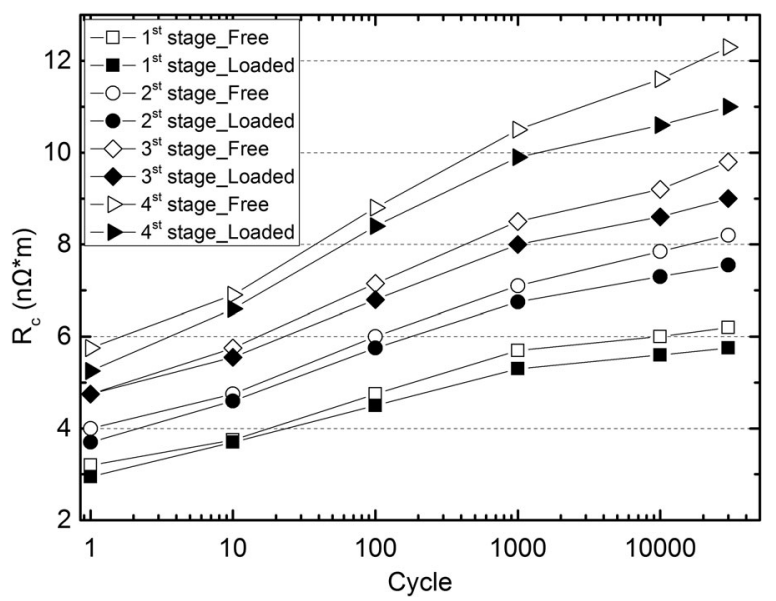

Fig. 5. Evolution of $R_{c}$ between different stages with cycles.

The data in Fig. 5 can be fitted by (3), which is also from [16]

$$
R_{c}=\left\{\begin{array}{l}
R_{c 0}+D \cdot e^{-F / F_{0}}(N \geq 2) \\
A_{0}+B_{0} \cdot F(N=1)
\end{array} .\right.
$$

Here $A_{0}, B_{0}, R_{c 0}, D$, and $F_{0}$ are fitted parameters. $R_{c 0}$ and $D$ are constant and the characteristic load $F_{0}$ is $130 \mathrm{kN} / \mathrm{m}$ for all the curves except for the first loading cycle. The simulation results represented by solid line are also shown in Fig. 4.

\section{B. Cyclic History Effect of Contact Resistance}

The measured $R_{c}$ of different cabling stages tends to increase linearly with load cycles and seems not to be saturated even at the maximum load cycle shown in Fig. 5. This behavior can be interpreted by the gradual separation of strands due to microsliding with increasing load cycles. The increase of copper resistivity may also play a partial role. This property of $R_{c}$ increase is beneficial because it enables a reduction of the coupling loss with load cycles.

\section{Correlation With Coupling Loss}

$L_{p}^{2} / R_{c}$ can give the preliminary estimation of the contribution of the cabling stages to the total coupling loss. The last stage 


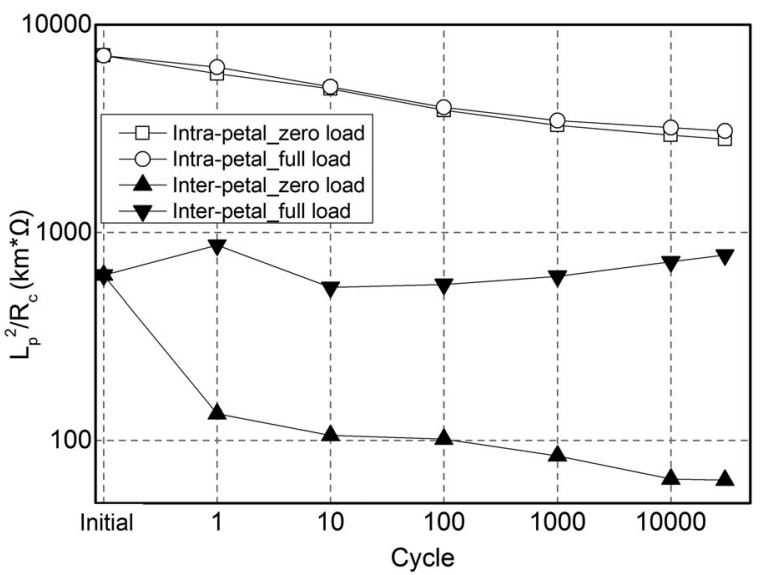

Fig. 6. $L_{p}^{2} / R_{c}$ at zero and full load versus load cycles.

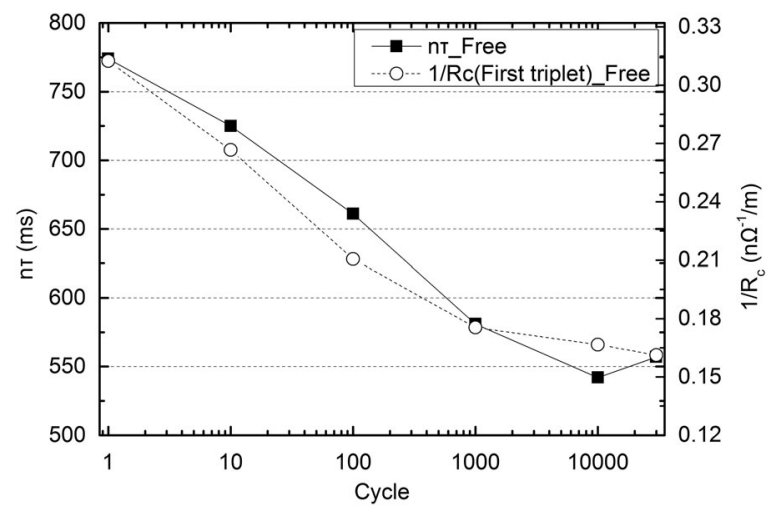

Fig. 7. Coupling loss time constant and $1 / R_{c}$ evolution as a function of cycle.

cable pitch of $\mathrm{Nb}_{3} \mathrm{Sn}$ conductor is $160 \mathrm{~mm}$ and the average intrapetal $R_{c}$ is $8.3 \mathrm{n} \Omega \cdot \mathrm{m}$ at full load after cycles based on the measurement, so $L_{p}^{2} / R_{c}$ is $3084 \mathrm{~km} / \Omega$ for the intrapetal. However, the petal pitch is $450 \mathrm{~mm}$ and the average interpetal $R_{c}$ is $260 \mathrm{n} \Omega \cdot \mathrm{m}$, which results in $L_{p}^{2} / R_{c}=779 \mathrm{~km} / \Omega$ at full load. Fig. 6 shows the evolution of $L_{p}^{2} / R_{c}$ in the different cabling stages with cycles. It is clear that the main contribution to the total coupling loss is intrapetal loss.

The relation between coupling loss time constant $(n \tau)$ and $R_{c}$ can be expressed as follows:

$$
n \tau=C \cdot \frac{1}{R_{c}}
$$

where $C$ is a constant depending on the cable pitch and conductor geometry. $n \tau$ is obtained by the slope of the loss-frequency curve at low frequency [22].

Fig. 7 shows the correlation between the evolution of the overall $n \tau$ and the first triplet's average $1 / R_{c}$ with cycles. Although $R_{c}$ is measured in the dc conditions and not completely a representative to the coupling current loops, a clear dependent correlation between intrapetal $R_{c}$ and coupling loss is found, which can give the accurate estimate of the coupling loss against cycle by using the measured $R_{c}$ results.

\section{CONCLUSION}

$\mathrm{A} \mathrm{Nb}_{3} \mathrm{Sn}$ CICC with STP cabling layout for the CFETRCSMC was measured under repetitive transverse mechanical loads in a cryogenic press at the University of Twente.

The mechanical properties were obtained from $d_{y}$ versus $F_{y}$ measurements with cycles simulating the real EM force cycles. It is found that the $d_{y}$ versus $F_{y}$ behavior is very different between the first and subsequent loading cycles. This mechanical property is explained by the combination of strand bending between crossovers and strand deformation at crossovers. Fitting models of $d_{y}$ versus $F_{y}$ and $E_{y}$ characteristics are also presented.

$R_{c}$ at different cabling stages was measured as well. The pressure and cyclic history effects of $R_{c}$ are discussed in relation with microsliding of strands and resistivity of the copper matrix. A clear correlation between intrapetal $R_{c}$ and coupling loss was found.

\section{ACKNOWLEDGMENT}

The authors would like to thank L. Guo for the key discussions on the correlation between $R_{\mathrm{c}}$ and coupling losses.

\section{REFERENCES}

[1] Y. Wan, "Mission of CFETR," in Proc. ITER Training Forum2nd Workshop MFE Develop. Strategy, Hefei, China, 2012.

[2] Y. Wan et al., "Design goal of the first option of CFETR," CFETR Design Document of Integral Group, Hefei, China, 2014.

[3] Y. Shi, Y. Wu, Q. W. Hao, B. Liu, and Y. Yang, "The AC loss evaluation of central solenoid model coil for CFETR," Fusion Eng. Des., vol. 107, pp. 100-107, 2016.

[4] B. Stepanov, P. Bruzzone, K. Sedlak, and R. Wesche, "Recent tests of the ITER conductors and highlights in $\mathrm{Nb}_{3} \mathrm{Sn}$ conductors behavior," IEEE Trans. Appl. Supercond., vol. 24, no. 3, Jun. 2014, Art. no. 4802105.

[5] A. Devred et al., "Status of conductor qualification for the central solenoid," IEEE Trans. Appl. Supercond., vol. 23, no. 3, Jun. 2013, Art. no. 6001208.

[6] Y. Shi et al., "DC performance measurement and assessment of $\mathrm{Nb}_{3} \mathrm{Sn}$ cable-in-conduit conductor for CFETR CS model coil," Fusion Eng. Des. vol. 126 , pp. 29-35, 2018

[7] N. Amemiya et al., "Influence of current re-distribution on minimum quench energy of superconducting triplex cable against local disturbance," Cryogenics, vol. 38, no. 5, pp. 559-568, 1998.

[8] Y. Nabara, T. Hemmi, and H. Kajitani, "Impact of cable twist pitch on $\mathrm{T}_{\mathrm{cs}}$ degradation and AC loss in $\mathrm{Nb}_{3}$ Sn conductors for ITER central solenoids," IEEE Trans. Appl. Supercond., vol. 24, no. 3, Jun. 2014, Art. no. 4200705.

[9] D. Bessette, "Design of a $\mathrm{Nb}_{3}$ Sn cable-in-conduit conductor to withstrand the 60000 electromagnetic cycles of the ITER central solenoid," IEEE Trans. Appl. Supercond., vol. 24, no. 3, Jun. 2014, Art. no. 4200505.

[10] J. Qin et al., "Optimization of CFETR CSMC cabling based on numerical modeling and experiments," Supercond. Sci. Technol., vol. 28, 2015, Art. no. 125008

[11] J. Qin, T. Xue, and B. Liu, "Cabling technology of $\mathrm{Nb}_{3} \mathrm{Sn}$ conductor for CFETR central solenoid model coil," IEEE Trans. Appl. Supercond., vol. 26, no. 3, Apr. 2016, Art. no. 4801305.

[12] A. Nijhuis, N. H. W. Noordiman, O. A. Shevchenko, H. H. J. ten Kate, and N. Mitchell, "Electromagnetic and mechanical characterisation of ITER CS-MC conductors affected by transverse cyclic loading, Part 3: Mechanical properties," IEEE Trans. Appl. Supercond., vol. 9, no. 2, pp. 165-168, Jun. 1999.

[13] W. Abbas, A. Nijhuis, Y. Ilyin, B. ten Haken, and H. H. J. ten Kate, "A fully automatic press for mechanical and electrical testing of full size ITER conductors under transverse cyclic load," AIP Conf. Proc., vol. 711, pp. 51-58, 2004.

[14] A. Nijhuis, Y. Ilyin, W. Abbas, B. ten Haken, and H. H. J. ten Kate, "Change of interstrand contact resistance and coupling loss in various prototype ITER NbTi conductors with transverse loading in the Twente Cryogenic Cable Press up to 40,000 cycles," Cryogenics, vol. 44, pp. 319-339, 2004. 
[15] Nijhuis and Y. Ilyin, "Transverse cable stiffness and mechanical losses associated with load cycles in ITER $\mathrm{Nb}_{3} \mathrm{Sn}$ and NbTi CICCs," Supercond. Sci. Technol., vol. 22, 2009, Art. no. 055007.

[16] J. Lu, V. Toplosky, K. Han, T. Adkins, S. T Bote, and R. P. Walsh, "The inter-strand contact resistance of $\mathrm{Nb}_{3} \mathrm{Sn}$ cable-in-conduit conductor with hydrocarbon coil," Supercond. Sci. Technol., vol. 21, 2008, Art no. 115011.

[17] Y. Miyoshi, G. Rolando, A. Vostner, Y. Nabara, and A. Nijhuis, "First results of AC loss test on ITER TF conductors with transverse load cycling," IEEE Trans. Appl. Supercond., vol. 22, no. 3, Jun. 2012, Art. no. 4804304.

[18] D. K. Oh et al., "Transverse load versus mechanical characteristics and inter-strand resistances in the cable of Option 2 specification for ITER TF conductor," IEEE Trans. Appl. Supercond., vol. 20, no. 3, pp. 495-498, Jun. 2010.
[19] A. Nijhuis and Y. IIyin, "Transverse load optimization in $\mathrm{Nb}_{3}$ Sn CICC design: Influence of cabling, void fraction and strand stiffness," Supercond. Sci. Technol., vol. 19, pp. 945-962, 2009.

[20] A. Nijhuis, N. H. W. Noordman, H. J. ten Kate, N. Mitchell, and P. Brooze, "Electromagnetic and mechanical characterization of ITER CS-MC conductors affected by transverse cyclic loading, Part 2: Interstrand contact resistances," IEEE Trans. Appl. Supercond., vol. 9, no. 2 pp. 754-757, Jun. 1999.

[21] M. Niewczas, Z. S. Basinski, and J. D. Embury, "The deformation of copper single crystals at 4.2 K," Mater. Sci. Eng., vol. 234-236, pp. 10301032, 2001.

[22] A. Nijhuis, H. H. J. ten Kate, P. Bruzzone, and L. Bottura, "Parametric study on coupling loss in subsize ITER $\mathrm{Nb}_{3} \mathrm{Sn}$ cabled specimen," IEEE Trans. Magn., vol. 32, no. 4, pp. 2743-2746, Jul. 1996. 